LA GRANJA:
REVISTA DE
CIENCIAS DE LA VIDA

DOI:10.17163/lgr.n23.2016.02
Artículo científico / Scientific paper

MANEJO DE SUELOS

\title{
DESCRIPCIÓN DEL MANEJO DE SUELOS EN SISTEMAS DE PRODUCCIÓN AGRÍCOLA DEL SECTOR HAMACA DE ANZOÁTEGUI, VENEZUELA
}

\author{
DESCRIPTION OF SOIL MANAGEMENT IN AGRICULTURAL PRODUCTION SYSTEMS \\ OF SECTOR HAMMOCK IN ANZOÁTEGUi, VENEZUELA
}

\section{Barlin Orlando Olivares*}

Investigador. Programa de Doctorado en Ingeniería Agraria, Alimentaria, Forestal y del Desarrollo Rural Sostenible. Universidad de Córdoba (UCO), España. Teléfono: +58 4243173568; Fax: +58 2432692621

*Autor para correspondencia: barlinolivares@gmail.com

Manuscrito recibido el 14 de marzo de 2016. Aceptado, tras revisión, el 29 de junio de 2016

\section{Resumen}

En el presente trabajo se aborda la descripción del manejo de suelos en los sistemas de producción agrícola a través del uso del método de Análisis de Componentes Principales (ACP), utilizando como paso particular el Sector Hamaca de la parroquia Atapirire, municipio Miranda del estado Anzoátegui. La metodología se fundamento en las visitas al azar a veinte unidades de producción agrícola. El instrumento de recolección de información fue la encuesta estructurada. Mediante el ACP se seleccionaron los primeros cinco componentes que explican el 93\% de la variación total. Se evidenció la poca rotación de cultivos, cultivos asociados en pequeñas áreas y ganadería extensiva. El manejo de suelos está orientado a la realización de las labores de cultivo en contenidos de humedad inadecuados; implementos poco adaptados al suelo, escasa presencia de residuos vegetales, quema de residuos y alto uso de enmiendas y agroquímicos.

Palabras claves: análisis de componentes principales, sustentabilidad, suelos.

\begin{abstract}
In this paper the description of soil management is addressed in agricultural production systems through the use of the method of Principal Component Analysis (PCA) using as a particular step Sector Hamaca Atapirire parish, municipality Miranda State Anzoátegui. The methodology is based on random visits to twenty units of agricultural production. The data collection instrument was a structured survey. PCA by the first five components explained $93 \%$ of the total variation was selected. The lack of crop rotation, intercropping in small areas and ranching are evident. Soil management is aimed at making the work of inadequate crop moisture content; implements ill-adapted to the ground, scarcity of plant residues, waste burning and amendments and high use of agrochemicals.
\end{abstract}

Keywords: principal component analysis, sustainability, soil. 
Forma sugerida de citar:

Olivares, B.. 2016. Descripción del manejo de suelos en sistemas de producción agrícola del sector Hamaca de Anzoátegui, Venezuela. La Granja: Revista de Ciencias de la Vida. Vol. 23(1): 14-24. ISSN: 1390-3799. 


\section{Introducción}

Según estudios realizados por el Ministerio del Ambiente y los Recursos Naturales (2005), Venezuela cuenta con apenas $2 \%$ de su territorio de tierras sin limitaciones para el desarrollo agrícola, mientras que el $98 \%$ presenta alguna limitación bien sea por relieve, baja fertilidad, mal drenaje y aridez o escasez de lluvia. Esta condición hace que la actividad agrícola, si no es llevada bajo preceptos de sostenibilidad, genere procesos de degradación que desmejoran significativamente la calidad de las tierras.

En este orden de ideas, en el país se han venido desarrollando, un conjunto de sistemas de producción, que responde a las condiciones de clima y suelos de las diferentes áreas productivas; la mayoría de ellos altamente dependientes del periodo lluvioso, predomina el monocultivo con poca diversidad genética, y con prácticas de manejo generalmente deficiente, a lo cual se atribuyen los indicios de degradación y contaminación de suelos y aguas y la vulnerabilidad debido a la homogeneidad de los materiales genéticos, destacan en ese sentido los cultivos anuales mecanizados (cereales y oleaginosas), desarrollados en zonas planas de mediana a alta fertilidad.

Los suelos tropicales son intervenidos por el hombre para realizar actividades agrícolas o pecuarias, iniciándose los procesos de degradación, caracterizados por la pérdida de las propiedades físicas, químicas y biológicas que bajo condiciones naturales, los mantenían en equilibrio con los factores agresivos del medio ambiente (Pla, 1990; Rodríguez y J.C.Rey, 2004).

De acuerdo a los aportes de Pla, (1988), Pla, (1990), Mogollón y Comerma, (1994), Rodríguez et. al., (1996), Fernández et. al., (1998), Rodríguez y Rey, (2004), las tierras de uso agrícola están severamente degradadas debido a un uso excesivo de maquinarias e insumos (fertilizantes y pesticidas), entre otros aspectos; las necesidades crecientes de tierras para desarrollos urbanos e industriales se cubren muchas veces a costa de pérdidas de tierras de alta capacidad agrícola esto ha sucedido con la mayoría de las tierras de la Mesa de Guanipa.

Bajo los lineamientos del Proyecto Nacional Simón Bolívar (2007-2021), se establece en esta nueva etapa, las bases solidas para la evaluación de los ecosistemas de sabana, y la generación de tecnologías para su aprovechamiento, teniendo como fundamento la preservación del medio ambiente y el uso racional de insumos. Obteniendo el desarrollo de proyectos orientados al estudio y generación de información que contribuyen a las mejoras de los sistemas agro-pastoriles o adopción de sistemas integrales que garanticen su sostenibilidad.

En la actualidad, el manejo sostenible de los suelos es una expresión cada vez más utilizada a nivel mundial para indicar, justamente, la excelencia en el tratamiento de las tierras con el propósito de obtener bienes y servicios de los ecosistemas sin comprometer el estado de sus recursos naturales renovables y su capacidad de resiliencia (Urquiza et. al., 2011). Esta investigación desarrollada en el sector Hamaca, promueve la caracterización de experiencias claves para el desenvolvimiento de prácticas adecuadas para el recurso suelo. En términos generales el objetivo de este estudio es describir el manejo del suelo en unidades de producción agrícola ubicadas en el sector Hamaca de la parroquia Atapirire del municipio Francisco de Miranda, proporcionando una base racional para el uso y manejo sostenible de este recurso.

\section{Metodología}

\subsection{Descripción del área de estudio}

El sector Hamaca está ubicado en la parroquia Atapirire del municipio Francisco de Miranda, estado Anzoátegui; posee un extensión de 6.473 hectáreas, con un altitud de 356 m.s.n.m y de latitud: 8.43352 y longitud: $-64,3706$ (Figura 1). Posee un clima tropical lluvioso (Aw) con vegetación típica de sabana, de acuerdo al sistema de clasificación de Köppen (Strahler y Strahler, 1989). Esta localidad se encuentra al sur del estado Anzoátegui, el cual tiene una marcada estacionalidad de la precipitación, debida a la acción alternada de la zona de convergencia intertropical. El periodo lluvioso concentra más del $85 \%$ del total anual de precipitación, mientras que en los meses secos llueve muy poco; es muy frecuente que en los meses de febrero y marzo la lluvia registrada sea de cero milímetros (Caraballo et al., 2005).

Los suelos representativos de esta parte del municipio Francisco de Miranda presentan un $\mathrm{pH}$ ácido entre 4,0-5,1; contenidos de fósforo inferiores a los $(5 \mu \mathrm{g} / \mathrm{g})$, calcio $(10-70 \mu \mathrm{g} / \mathrm{g})$, magnesio $(5-60 \mu \mathrm{g} / \mathrm{g})$, potasio $(10-30 \mu g / g)$, hierro $(0,5-30 \mu g / g)$, manganeso $(0,5-12 \mu g / g)$, cinc $(0,1-1 \mu g / g)$, bajos contenidos de Materia Orgánica $(0,1-1,3 \%)$, aluminio intercambiable entre $0,1-1 \mathrm{meq} / 100 \mathrm{~g}$ de suelo y conductividad eléctrica entre 0,1 y 0,3 ds / m. Estos suelos corresponden a los órdenes Entisoles, Ultisoles y Oxisoles (grandes grupos Quartzipsamments, Kandiustuits y Haplustox). 


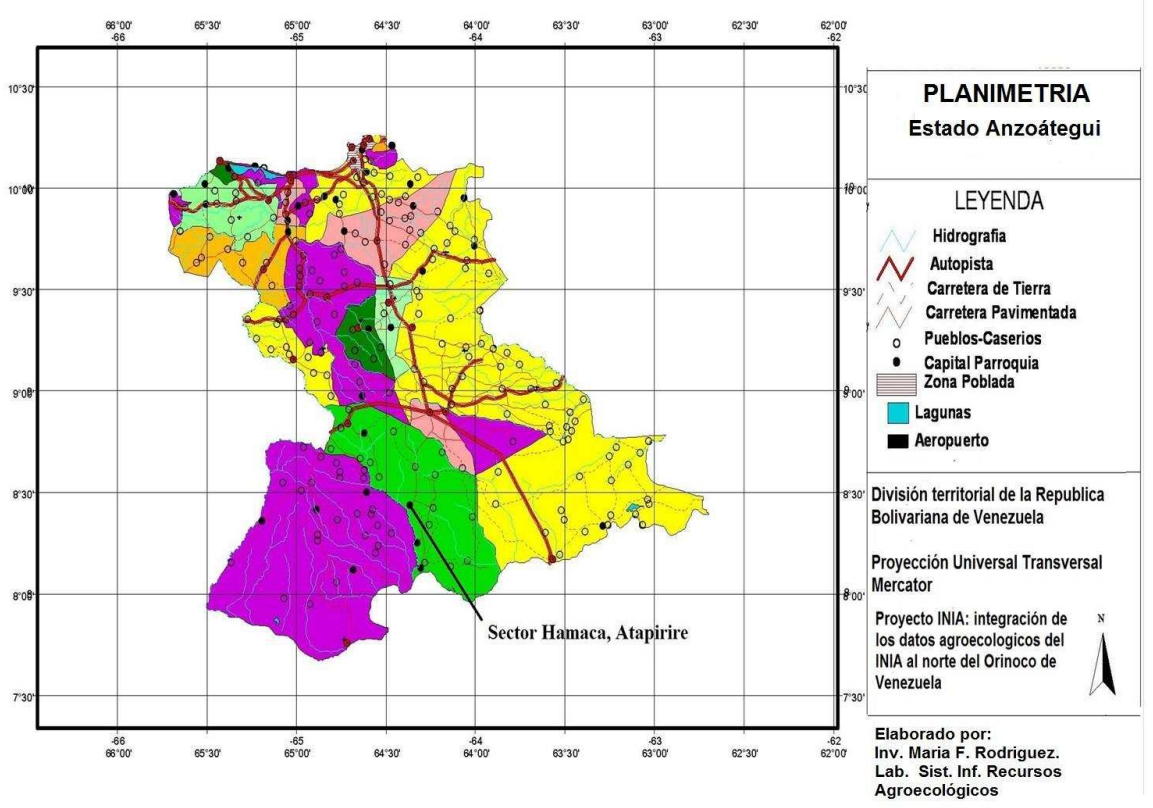

Figura 1. Ubicación del sector Hamaca, parroquia Atapirire del municipio Francisco de Miranda, Anzoátegui, Venezuela (Fuente: Rodríguez y Rey, 2004)
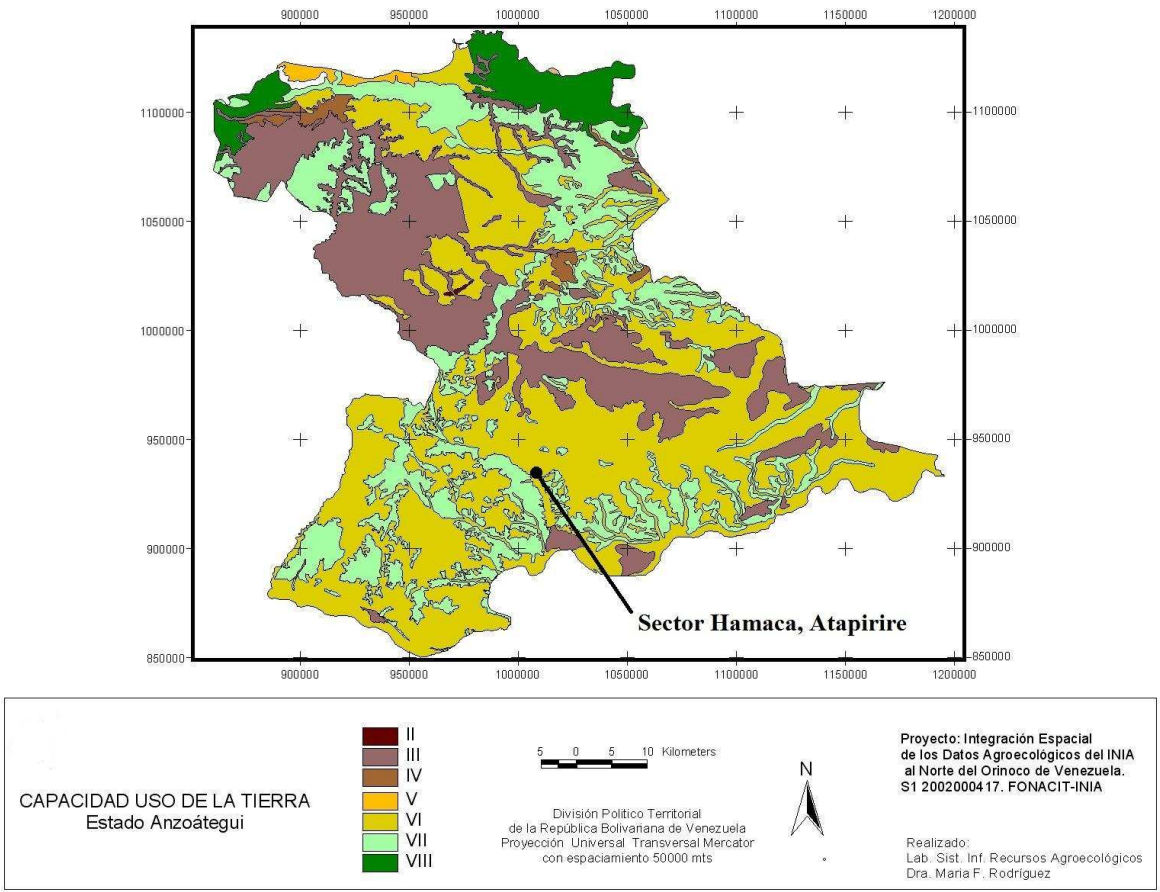

Figura 2. Capacidad de uso de las tierras en la Mesa de Guanipa, Anzoátegui. (Fuente: Rodríguez y Rey, 2004) 
La Figura 2 muestra la clasificación de tierras en el estado Anzoátegui, de acuerdo a su capacidad de uso según Comerma y Arias (1971). Dentro de las principales ventajas, Mogollón y Comerma (1994), Rodriguez et. al., (1996), señalan las extensas áreas planas que no requieren de costosas inversiones en adecuación de tierras; los suelos livianos y profundos, de fácil mecanización, lo cual permite el cultivo de grandes áreas; suelos bien drenados, facilitando el ingreso de maquinarias al terreno poco tiempo después de ocurrir las lluvias; agua subterránea abundante y de buena calidad.

La vegetación típica de las sabanas, está representada por gramíneas y algunas especies arbustivas, por su ubicación dentro de la zona de vida conocida como bosque seco tropical (Holdridge, 1957). Esta vegetación es bastante pobre en cuanto a densidad, pero su composición es variada. Primeramente es de notar la escasez de vegetación alta, cuyas especies más importantes son las que se mencionan en la Tabla 1.

Tabla 1. Vegetación característica de las sabanas orientales, Anzoátegui, Venezuela.

\begin{tabular}{ll}
\hline \multicolumn{1}{c}{ Nombre vulgar } & \multicolumn{1}{c}{ Nombre científico } \\
\hline Chaparo curata & Curatela americana \\
Alcornoque & Bowdichia virgilioides \\
Tortolito & Casearia silvestris \\
Chaparro Manteco & Byrsonima crassifolia \\
Merey & Anacardium ocidentale \\
\hline
\end{tabular}

El relieve se caracteriza por la presencia de grandes extensiones planas, interrumpidas en la zona central por los bordes mesa, algunos de estos bordes mantienen su perpendicularidad, a pesar de estar sometidos a intensos procesos erosivos que han ido suavizando esta forma de relieve. También se puede decir que son llanuras disectadas, el paisaje predominante es la altiplanicie de la mesa disectada, con limitaciones de relieves quebrados que corresponden de relieves planos a relieves moderadamente disectados.

En general esta localidad pertenece a una de las zonas de importancia agrícola en el sur de Anzoátegui, este último es considerado uno de los estados venezolanos de gran relevancia para el desarrollo agrícola, tanto por su extensión como por el potencial de sus tierras, especialmente en las áreas de valles, planicies aluviales y mesas no disectadas. Las unidades de tierra de la zona de interés se encuentran bajo diferen- tes usos agropecuarios tales como: Fríjol (Vigna sinensis), Maíz (Zea mays), Ganadería (pasto), Soya (Glicine max), Sorgo (Sorghum bicolor) y Yuca (Manihot esculenta) entre otros.

\subsection{Análisis multivariado por componen- tes principales}

Los resultados de la información recolectada en las unidades de producción encuestadas fueron analizados mediante el Análisis de Componentes Principales $(\mathrm{ACP})$, el cual representa una técnica matemática que no requiere un modelo estadístico para aplicar la estructura probabilística de los errores. Este análisis es aplicado cuando se desea conocer la relación entre elementos de una población y se sospecha que en dicha relación influye de manera desconocida un conjunto de variables o propiedades de los elementos (Pla, 1986; Demey et al., 1994, 1995; Ramos et al., 2004).

(Demey et al., 1994) indican que mediante el ACP se pueden encontrar nuevas variables denominadas $Y(k), k=1, \ldots, p$; que sean combinaciones lineales de las variables originales $X(j)$, en el estudio de un conjunto de $(n)$ individuos, donde se le imponen a este sistema ciertas condiciones que permitan satisfacer los objetivos del análisis por componentes principales. Por su parte Pla (1986) señala en la Ecuación 1, que esto implica encontrar $(p \times p)$ constantes tales que:

$$
Y(k)=\sum_{j=1}^{p} l(j k) X(j) \quad k=1, \ldots, p .
$$

Donde $l_{(j k)}$ es cada una de esas constantes. Debido a la sumatoria, en cada nueva variable $Y_{(k)}$ intervienen todos los valores de las variables originales $X_{(j)}$. El valor numérico de la $l_{(j k)}$ indicará el grado de contribución que cada variable original aporta a la nueva variable definida por la transformación lineal. Puede expresarse la transformación lineal de componentes principales en términos matriciales: $Y_{(n \times p)}=$ $X_{(n \times p)} L_{(p \times p)}$.

La metodología realizada se basó en técnicas de generación de datos, tanto cualitativos como cuantitativos, mediante una encuesta estructurada considerando características sociodemográficas y del ámbito legal o jurídico en la comunidad, con preguntas con respuestas indicadas binominalmente. El diseño de la encuesta se realizó siguiendo los lineamientos propuestos en distintos trabajos realizados en el área por investigadores tales como Letson et. al., (2001), Eakin y Conley (2002) y Rivarola et. al., (2002). Este es- 
tudio está referido a veinte productores y productoras responsables, encargados de las unidades de producción agrícola (10 encuestados en el primer semestre del 2013 y los otros 10 encuestados en el primer semestre del 2014). El Instrumento seleccionado para obtener la información fue el cuestionario, a través de la cual se recogieron datos para un total de 13 variables.

Las variables consideradas estuvieron relacionadas a dos aspectos, el primero relacionado con las características de producción y manejo de suelo en la finca: edad del fundo (EDF), superficie aprovechable (SUP), tipo de cultivo (TDC), asociación de cultivo (ADC), riego (RIE), asociación agricultura-ganadería (GYA), tipo de maquinaria (MAQ), uso de maquinaria pesada (MPES), contenido de humedad adecuado para las labores de preparación de suelo (ChumA), aplica abono orgánico (AAO), practica la quema de residuos de cosecha (PQR), Conoce los productos biológi$\cos (\mathrm{CPB})$, aplicación de productos biológicos (APB).

La matriz de datos $X$ está constituida por el conjunto de vectores de las observaciones $X_{[i j]}, j=1, \ldots, p$ y donde cada vector $X_{[i j]}$ presenta la variable j-ésima para todas las observaciones y donde $X$, es la matriz de datos formada por " $n$ " observaciones con " $p$ " variables (20 observaciones por 13 variables estudiadas).

Utilizando el software Infostat versión 9.0 (2008), se generaron los valores propios y proporción de la varianza explicada calculada a partir de la matriz de correlación; la proporción de la variación original explicada por cada componente principal de la matriz de correlación o matriz de determinación. El mismo programa genera el gráfico tipo $X Y$ entre el primer y los demás componentes principales.

\section{Resultados y discusiones}

Para seleccionar el número de componentes a incluir se utilizó el criterio de Kaiser, que incluye sólo aquellos cuyos valores propios fueron mayores a 1 (Demey et al., 1994); en este estudio, el análisis muestra cinco componentes que explican el $93.0 \%$ de la variación, considerada como una proporción significativa del total, tal como se indica en la Tabla 2. Los componentes resultantes en este estudio representan el resultado de una combinación lineal de las variables en donde cada una tiene una ponderación diferente, en proporción a las magnitudes de cada elemento que conforma el autovector respectivo.
Tabla 2. Valores propios y proporción de la varianza explicada calculada a partir de la matriz de correlación.

\begin{tabular}{cccc}
\hline Componente & Valor & Proporción & $\begin{array}{c}\text { Proporción } \\
\text { acumulada }\end{array}$ \\
\hline 1 & 4,14 & 0,32 & 0,32 \\
2 & 3,41 & 0,26 & 0,58 \\
3 & 2,04 & 0,16 & 0,74 \\
4 & 1,45 & 0,11 & 0,85 \\
5 & 1,01 & 0,08 & 0,93 \\
6 & 0,59 & 0,05 & 0,97 \\
7 & 0,28 & 0,02 & 0,99 \\
8 & 0,08 & 0,01 & 1,00 \\
\hline
\end{tabular}

Tabla 3. Correlaciones con las variables originales.

\begin{tabular}{lccccc}
\hline & \multicolumn{5}{c}{ Componentes Principales } \\
\cline { 2 - 6 } Variables & C1 & C2 & C3 & C4 & C5 \\
\hline EDF & $-0,2$ & $-0,44$ & $-0,04$ & 0,19 & $-0,26$ \\
SUP & $-0,13$ & $-0,18$ & $-0,41$ & 0,57 & 0,02 \\
TDC & 0,25 & 0,05 & $-0,35$ & 0,22 & 0,52 \\
ADC & 0,11 & $-0,31$ & 0,19 & $-0,52$ & 0,05 \\
RIE & $-0,18$ & 0,37 & 0,22 & 0,06 & 0,45 \\
MAQ & 0,02 & 0,46 & $-0,26$ & $-0,12$ & $-0,34$ \\
GYA & 0,25 & 0,22 & 0,41 & 0,2 & 0,24 \\
MPES & 0,41 & $-0,09$ & 0,25 & 0,27 & $-0,14$ \\
CHumA & $-0,34$ & 0,33 & 0,13 & 0,15 & $-0,2$ \\
AAO & $-0,41$ & 0,09 & $-0,25$ & $-0,27$ & 0,14 \\
PQR & 0,46 & $-0,03$ & $-0,19$ & $-0,11$ & $-0,1$ \\
CPB & $-0,22$ & $-0,06$ & 0,44 & 0,27 & $-0,19$ \\
APB & $-0,25$ & $-0,39$ & 0,11 & $-0,04$ & 0,41 \\
\hline
\end{tabular}

En función a lo descrito anteriormente, el primer componente es aquel que posee el mayor porcentaje de aporte a la varianza de la respuesta y en consecuencia explicitaría la mayor capacidad de los datos en el estudio, la cual es de $32.0 \%$ del total. Al revisar la matriz de correlación de las variables originales (Tabla 3) se observa que dos características que determinan la mayor variabilidad en este componente son: la práctica de quema de residuos con $46.0 \%$ y el uso de la maquinaria pesada para realizar la preparación de suelo (MPES) con un coeficiente de $41.0 \%$. 

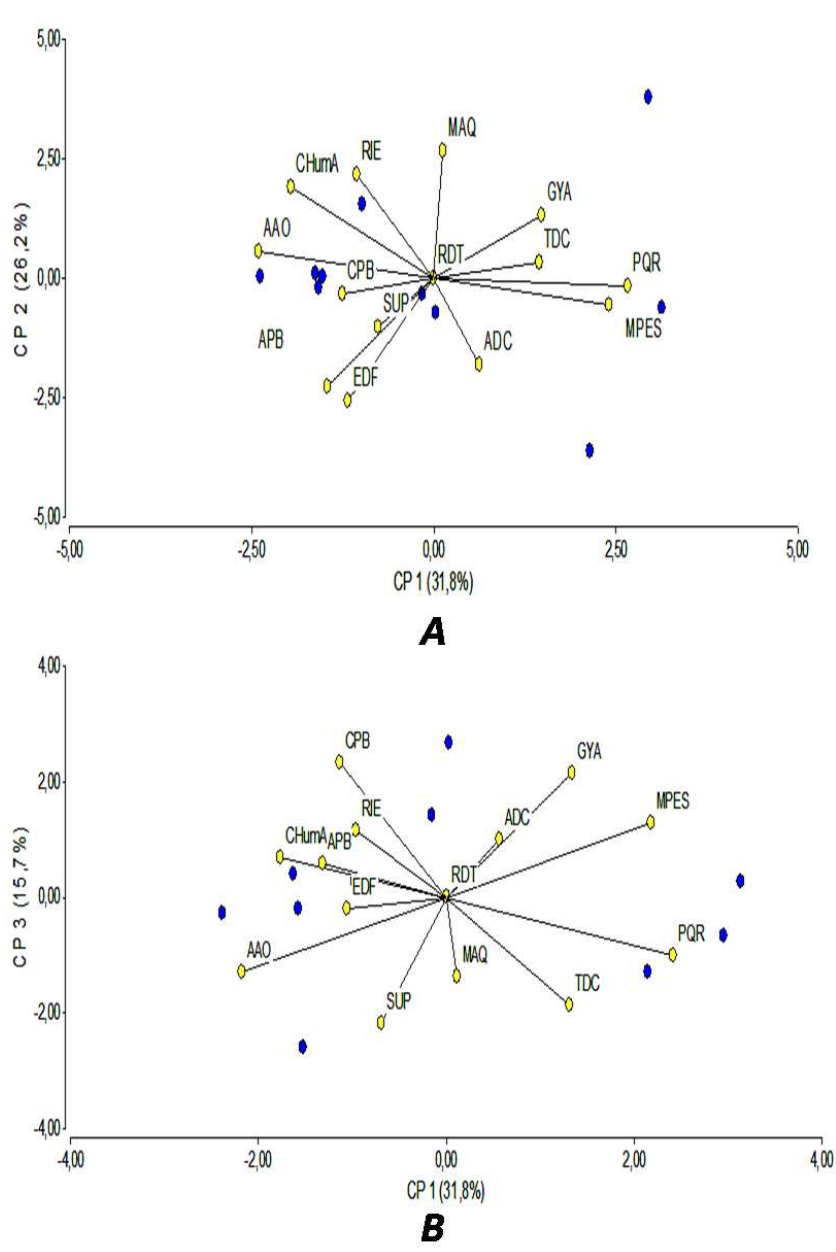

Figura 3. Representación bivariada de las variables asociadas a los dos primeros componentes principales. (A). primer y segundo componente. (B). primer y tercer componente.

La mayoría de los productores encuestados manifestaron practicar la quema de residuos de cosecha en la zona. El fuego en las sabanas, puede originarse de manera natural o provocada como una práctica cultural, afecta anualmente parte importante de estas formaciones vegetales. En este orden de ideas, cierto tipo de sabanas presentan una capacidad de recuperación vigorosa después de sufrir los impactos causados por la quema, sin embargo algunas inspecciones en la zona de estudio evidenciaron que la recuperación de la vegetación se lleva a cabo de manera lenta. Por otra parte, en la actualidad ocurre un proceso progresivo de eliminación física de sabanas para dar lugar a potreros o áreas cultivables en la localidad bajo estudio.

Con relación al segundo componente, este explica un $26.0 \%$ de la variabilidad total, relacionado con el riego (37.0\%) y el contenido de humedad del suelo al momento de hacer las labores en campo (33.0\%). De acuerdo a lo anterior, el riego por medio del pivote central en esta zona y en otras de la Mesa de Guanipa solo es utilizado por aquellos productores con grandes extensiones de tierras cultivadas, por lo general cereales y leguminosas. Por su parte, los productores que desarrollan la agricultura de secano están sujetos a los periodos de disponibilidad de humedad en la zona, sin embargo, la mayoría de los entrevistados manifestaron que realizan la preparación de suelos incluso fuera de los periodos de humedad adecuados para estas condiciones de clima, esto se debe principalmente a el retraso en los créditos agrícolas por medio de los organismos oficiales y en ocasiones por desconocimiento del régimen de lluvias en el área de estudio o incluso por la variabilidad natural de la precipitación.

En la Figura 3a, se muestran las variables asociadas a los dos primeros componentes, entre las cuales las variables: uso de maquinaria pesada y la quema de residuos son las que mayormente intervienen en esta asociación.

El tercer componente interpreta el $16.0 \%$ de la variabilidad total. Esta referido a la variable asociada al conocimiento de los productos biológicos para el manejo de cultivo $(44.0 \%)$ y la asociación de la agricultura con la ganadería $(41.0 \%)$. En la relación con el uso agrícola, los principales cultivos anuales que han desarrollado en la zona de estudio son: Sorgo (Sorghum vulgares L.) Maní (Arachis hipogea L), Caraota (Phaseolus vulgaris), Patilla (Citrullus lanatus), así como algunas hortalizas en zonas cercanas a ríos y morichales, en la actualidad solo la patilla y la yuca es considerado un cultivo rentable. La superficie sembrada ha disminuido drásticamente en algunos casos y en otros se ha dejado de sembrar totalmente. La falta de recursos económicos y problemas en la comercialización, han sido las causas principales de la casi desaparición de la actividad agrícola en la zona.

En la Figura 3b, se muestran las variables asociadas al primer componente y su relación con el tercer componente. La problemática ya descrita ha obligado a los productores a apoyarse en la ganadería, por tener esta región mayor capacidad de ajuste a los vaivenes económicos y políticas del estado. Esto plantea la necesidad de establecer pastizales al menor costo posible.

Actualmente las explotaciones pecuarias representan el uso más generalizado de la tierra y se utilizan principalmente las especies nativas que tienen baja capacidad de carga animal como fuente de alimentación. 
Sin embargo, los productores de mayores recursos

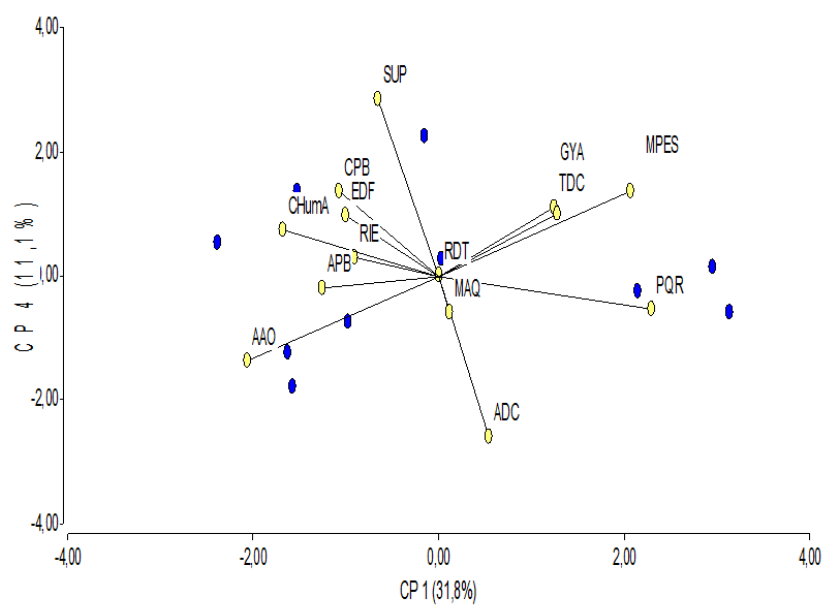

$\boldsymbol{A}$

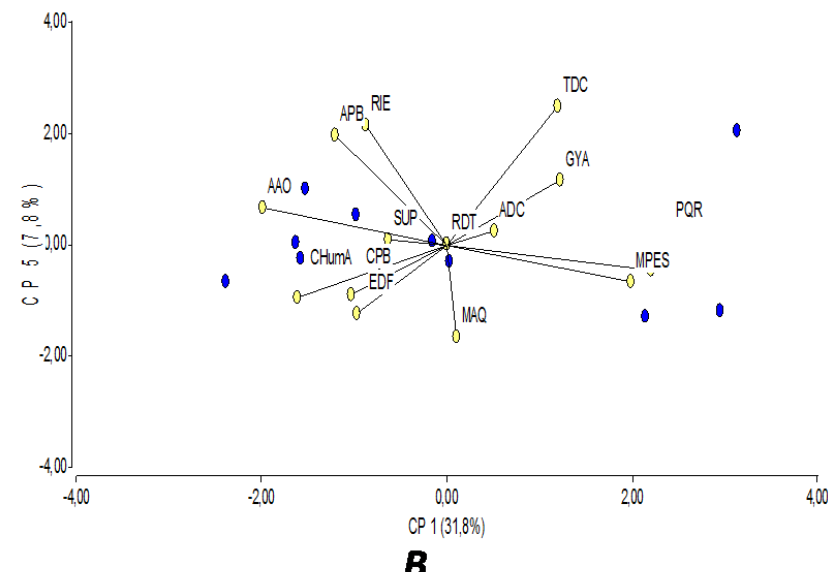

Figura 4. Representación bivariada de las variables asociadas del primer componente. A. primer y cuarto componente. B. primer y quinto componente.

han introducido especies forrajeras como: suazi ( $D i$ gitaria swazilandensis), Barrera (Brachiaria decumbens), Brizantha (Brachiaria Brizantha), pasto aguja (Brachiaria humidicola).

El cuarto componente representa un $11.0 \%$ de la variabilidad total. Se presenta con valor positivo las variable asociada a la superficie aprovechable (57.0\%). Por lo general en el área de estudio las superficies aprovechables van desde 100 a 200 ha.

Las sabanas orientales, son el asiento de la actividad ganadera. Es en ella donde se practica la ganadería extensiva; es decir, la cría de ganado vacuno en grandes extensiones de tierra. Este tipo de ecosistema se caracteriza por presentar un tipo de vegetación integrada por variedades de gramíneas que constituyen el alimento natural (pastos) del ganado. Sin embargo, la riqueza alimentaria de algunas de ellas es baja, esto es debido a la pobreza de los suelos. Tal característica, asociada al tipo de ganadería que se practica; es decir, la extensiva o tradicional, hace necesaria la existencia de grandes extensiones de terreno para la alimentación de los rebaños, porque deben pastar libremente. Por eso, se pueden observar latifundios, es decir, grandes extensiones de tierra en manos de un propietario.

Por último, el quinto componente explica el 8.0\% de la varianza total, referido a la variable: Tipo de cultivo $(52.0 \%)$ y la aplicación de productos biológicos $(41.0 \%)$. En su mayoría, los sistemas de producción de la zona son agrícolas, desarrollando diferentes cultivos y gramíneas para la alimentación animal.

Las Figuras 4a y 4b, muestran que los sistemas de producción están representados por un conjunto de actividades agrícolas, pecuarias y no agrícolas. Por lo tanto, pueden ser caracterizados como una combinación de diversos subsistemas en Atapirire. En primer lugar, los sistemas de cultivos: definidos al nivel de las parcelas, explotadas de manera homogénea, con las mismas tecnologías y sucesiones de cultivos. También los sistemas de crianza, definidos al nivel de los hatos o rebaños, incluyendo los sistemas de transformación, representados por los productos agropecuarios (transformación de cereales, fabricación de quesos, entre otros); y por último, las actividades no agrícolas: pequeños negocios, artesanía, venta de fuerza de trabajo en la ciudad, y las actividades domésticas que contribuyen a la reproducción del sistema de producción.

Los distintos componentes se resumen en la (Tabla 4), de acuerdo a su importancia y significación. En términos generales se puede observar que a medida que la proporción de la varianza se aleja del componente principal, es explicado en un sentido amplio por las variables más relevantes de los componentes. En síntesis, del análisis de la matriz de correlación entre las variables originales y los componentes principales, se puede observar que los valores más altos del primer componente, son los que determinan la precisión con respecto al manejo de suelos en las unidades de producción del Sector Hamaca.

En función a lo anterior Pla (1988) señala que se requiere urgente decisiones en cuanto al uso racional de la tierra, tanto de nuevos desarrollos agrícolas como cuando se requiera introducir cambios en su uso y manejo. Estas decisiones deben basarse en medios efectivos para evaluar y manejar los limitados recursos de suelos aptos para la agricultura en Venezuela. 
Tabla 4. Interpretación de los primeros cuatro componentes principales vía matriz de correlación (R).

\begin{tabular}{lcl}
\hline Componente & $\begin{array}{c}\text { Porcentaje de } \\
\text { explicación }\end{array}$ & Interpretación \\
\hline $\begin{array}{l}\text { Primero } \\
\text { Segundo }\end{array}$ & 32.0 & $\begin{array}{l}\text { Uso de maquinaria pesada y la quema de residuos } \\
\text { Uso del riego y contenido de humedad adecuado del suelo para las la- } \\
\text { bores agrícolas } \\
\text { Tercero }\end{array}$ \\
$\begin{array}{lll}\text { Asociación de la ganadería y agricultura, Conocimiento de los productos } \\
\text { biológicos para el manejo de cultivo } \\
\text { Cuarto }\end{array}$ & 16.0 & $\begin{array}{l}\text { Superficie aprovechable } \\
\text { Tipo de cultivo y aplicación de productos biológicos }\end{array}$ \\
\hline
\end{tabular}

Total de varianza $\quad 93.0 \%$

De acuerdo a Rodríguez et. al., (1996) En la región de estudio no hay tradición en el uso de sitemas agropastoriles, lo común ha sido una división evidente entre el agricultor y el ganadero. El primero se ha dirigido hacia el monocultivo, con utilización intensiva de abonos, plaguicidas, el maquinismo y un pequeño número de especies y de variedades vegetales; mientras que el segundo ha sustentado su explotación en los pastos nativos y/o cultivados. Sin embargo, se han observado experiencias como: el establecimiento de pastas mediante siembra simultánea con cultivos como sorgo y maíz, que ha resultado una práctica muy común en la región; y la siembra de merey intercalado con pastos del género Brachiaria.

Al analizar la crisis del sector agropecuario estatal, y evaluar la permanencia de los sistemas de producción, se hace evidente que una de las explotaciones que han sobrevivido a ella es la ganadería bovina para carne, que es una de las más importantes y constituye la opción más favorable a tenerse en cuenta en un sistema de producción agropastoril.

El uso y manejo sostenible del suelo deben mantener la potencialidad biofísica del suelo y al mismo tiempo permitir la diversificación del sistema agrícola de explotación considerándose, en primer lugar la expansión de la superficie agrícola, la introducción de variedades mejoradas, el uso de técnicas de riego, la aplicación de fertilizantes orgánicos y biofertilizantes y por último, la racionalización de prácticas de laboreo fundamentalmente.

Las altas aplicaciones de fertilizantes y enmiendas, junto al control de plagas y enfermedades, han sido aspectos de los paquetes tecnológicos que han dado lugar a un uso elevado de agrotóxicos e intensiva mecanización agrícola, generando problemas de degra- dación de suelos en el oriente venezolano (Torres et. al., 2005). La aplicación de fertilizantes nitrogenados y fosfatados inorgánicos de forma excesiva inhiben los procesos que sustentan la fertilidad natural de los suelos, mientras que el manejo agroecológico puede favorecerlos (España et. al., 2006, López et. al., 2007; Toro et. al., 2008, López, 2010); lo cual permite a los cultivos expresar mecanismos tales como exudación de ácidos orgánicos, activación de enzimas como la fosfatasa ácida y cambios en el pH del suelo, mejoras en la estructura del suelo, entre otros (López et. al., 2010).

Es importante señalar que cualquier suelo puede soportar cualquier tipo de uso agrícola siempre que se le suministren los inputs necesarios (Rodríguez et. al., 1996). Éstos pueden ser de tal magnitud que determinen las condiciones básicas de explotación, ya que cada unidad de tierra cuenta con sus propias potencialidades y limitaciones y cada tipo de uso con sus propios requerimientos biofísicos. Puesto que el objetivo fundamental en la protección del suelo es minimizar costos socio-económicos y ambientales mediante la predicción de la capacidad inherente de cada unidad de tierra para soportar el uso y manejo específicos durante un largo plazo de tiempo sin causar deterioro. La protección del suelo requiere mejorar el uso agrícola del mismo a través de la planificación y el manejo sostenibles (De la Rosa et. al., 2004, López et. al., 2010).

\section{Conclusiones}

De acuerdo a la información suministrada por los productores en la Mesa de Guanipa, el manejo del suelo se desarrolla en función a las limitaciones o están relacionadas con la textura arenosa de sus primeros hori- 
zontes, lo que implica que estos suelos presentan bajo contenido de elementos químicos esenciales como $\mathrm{Ca}, \mathrm{Mg}, \mathrm{K}$ y P, lo cual representa la justificación por la aplicación excesiva de fertilizantes y de enmiendas, así mismo, los suelos de esta región mayormente son de reacción acida y de baja capacidad de retención de humedad, lo cual genera como mayor consecuencia la disminución de la eficiencia de la fertilización que realizan dichos productores. Se observó en los recorridos realizados en las unidades de producción que los suelos presentan débil estructura, bajo contenido de materia orgánica, que en conjunto con las condiciones climáticas de fuertes lluvias y vientos, facilitan los procesos de encostramiento, escurrimiento superficial y erosión hídrica en las zonas con poca o escasa cobertura vegetal.

De acuerdo a las entrevistas, se determinó que estos suelos de las sabanas orientales presentan cierta susceptibilidad a la compactación del subsuelo específicamente, debido en esencia tanto a las propiedades físicas como al uso excesivo de maquinarias y presencia de grava en horizontes cercanos a la superficie. Esto genera principalmente problemas con la facilidad de penetración del sistema radical en las plantas. En general la actividad tanto agrícola como pecuaria en la Mesa de Guanipa no ha sido manejada de manera correcta debido a la falta de asistencia técnica o capacitación dirigida a los productores, sin embargo las políticas gubernamentales que se han llevado a cabo en la última década han estado enmarcadas en tener una agricultura sustentable donde el hombre así como también el ambiente, se benefician de la mejor manera, es decir, utilizando productos biológicos tale como: (humus, Trichoderma sp, bacterias antagonistas, extractos naturales, entre otros) logrando de esta manera la obtención de alimentos más saludables para el consumo humano.

\section{Referencias}

Caraballo, L., M. Pérez y M. Marcano. 2005. Régimen y distribución de las lluvias en El Tigre, estado Anzoátegui, Venezuela. Boletín Geominas. 3(37): 6772 .

Comerma, J. y L. F. Arias.. 1971. Un sistema para evaluar las capacidades de uso agropecuario de los terrenos en Venezuela. En: I Seminario sobre clasificación interpretativa de suelos con fines agropecuarios. Sociedad Venezolana de la Ciencia del Suelo (Mimeografiado). Maracay.
De La Rosa, D., F. Mayol, E. Díaz-Pereira, M. Fernández y D. Jr. De La Rosa. 2004. A land evaluation decision support system (MicroLEIS DSS) for agricultural soil protection. Environmental Modelling \& Software. (19): 929-942. URL: www.micoleis.com, Consulta: 18 de abril de 2011.

Demey, J., Y. Prada y L. Pla. 1995. Grupo de estaciones con patrones homogéneos de precipitación del estado Falcon-Venezuela. Agronomía Trop. 45(1): 95-120. URL: http:/ /sian.inia.gob.ve/repositorio/revistas_ci/ Agronomia\%20Tropical/at4501/arti/demey_j.htm, Consulta: 07 de febrero de 2011.

Demey, J. R., M. Adams y H. Freites. 1994. Uso del método de análisis de componentes principales para la caracterización de fincas agropecuarias. Agronomía Trop. 44(3): 475-497. URL: http://sian.inia.gob.ve/repositorio/revistas_ci/ Agronomia\%20Tropical/at4403/Arti/demey_j.htm, Consulta: 07 de febrero de 2011.

Eakin, H. y J. Conley. 2002. Climate variability and the vulnerability of ranching in southeastern Arizona: a pilot study. Clim Res. (21): 271-281.

España, M., E. Cabrera de Bisbal y M. López. 2006. Study of nitrogenfixation by tropical legumes in acid soil from venezuelan savannas using $15 \mathrm{~N}$. Interciencia. 31(3): 197-201.

Fernández, F. y J. Rey. 1998. Aplicación de un sistema informático integrado la evaluación de la degradación medio ambiental el trópico. Maracay. Venezuela. Memorias: 117.

Holdridge, L.. 1957. Determination of world plant formation from simple climatic data. Science. 105(27): 367-368.

Infostat. 2008. Infostat for Windows Version 9.0. Grupo Infostat. Inc. Facultad de Ciencias Agricolas. Universidad. Nacional de Córdoba. Argentina.

Letson, D., I. Llovet, G. Podesta, F. Royce, V. Brescia, D. Lema y G. Parellada. 2001. User perspectives of climate forecast: crop producers in Pergamino, Argentina. Clim Res. (19): 57-67.

López, M.. 2010. Manejo agroecológico del sistema sorgo-frijol. Efecto sobre la fertilidad del suelo y microorganismos con potencial para biofertilizar agroecosistemas venezolanos. Tesis de doctora- 
do. Postgrado en Ciencia del Suelo. Maracay, Ven. Universidad Central de Venezuela. página 210.

López, M., I. López de Rojas, M. España, A. Izquierdo y L. Herrera. 2007. Efecto de la fertilización inorgánica sobre la disponibilidad de nutrimentos en el suelo, nivel nutricional de la planta y hongos micorrizícos arbusculares en plantaciones de Theobroma cacao L. Agronomía Trop. 57(1): 31-43.

López, M., B. Rodríguez y M. España. 2010. Tecnologías generadas por el Inia para contribuir al manejo integral de la fertilidad del suelo. Agronomía Tropical. 60(4): 315-330.

Ministerio del Ambiente y los Recursos Naturales (MARN). 2005. Primera Comunicación Nacional en cambio climático de Venezuela. Programa de las naciones unidas para el desarrollo. Fondo Mundial para el medio ambiente: 135 .

Mogollón, Y. y J. Comerma. 1994. Suelos de Venezuela. Editorial Exlibris. Maracay. Venezuela.

Pla, I.. 1990. La degradación y el Desarrollo agrícola de Venezuela. Agronomía Tropical. 40: 7-27.

Pla, I.. 1998. Desarrollo de índices y modelos para el diagnóstico y prevención de la degradación de suelos agrícolas en Venezuela. Ediciones Banco Consolidado. Caracas Venezuela. página 40.

Pla, L.. 1986. Análisis multivariado: método de componentes principales. Departamento de asuntos científicos y tecnológicos. Organización de Estados Americanos. Washington, D.C. EE.UU. página 97.

Ramos, C., M. A. Gomez y A. De Ascencao. 2004. Caracteres morfológicos determinantes en dos poblaciones de cacao criollo del occidente de Venezuela. Agronomía Trop. 54(1): 45-62. URL: http:/ / www.scielo.org.ve/scielo.php?script=sci_ arttext\&pid=S0002-192X2004000100004\&lng=es\& nrm=iso, Consulta: 20 de abril de 2011.

Rivarola, A., M. Vinocur y R. Seiler. 2002. Uso y demanda de información agrometeorológica en el sector agropecuario del centro de la Argentina. Rev. Arg. De Agrometeorología. 2(2): 143-149.

Rodríguez, M. y J.C.Rey. 2004. Delimitación de zonas frágiles de Venezuela. (Mimeografiado). INIACENIAP. página 11.

Rodríguez, T., D. Sanabria y L. Navarro. 1996. Nuevos enfoques en el Manejo de Sabanas en los Llanos Orientales Venezolanos. Centro de Investigaciones Agropecuarias del Estado Anzoátegui. Rev. Divulga. 52. URL: http:/ /sian.inia.gob.ve/repositorio/revistas_tec/ FonaiapDivulga/fd52/sabanas.htm, Consulta: 20 de abril de 2011.

Strahler, A. y A. Strahler. 1989. Geografía Física. España: Editorial Omega S.A. Tercera Edición.

Toro, M. y I. B. M.Â López. 2008. Micorrizas arbusculares y bacterias promotoras del crecimiento vegetal, biofertilizantes nativos de sistemas agrícolas bajo manejo conservacionista. Agronomía Trop. 58(3): 215-221.

Torres, R. y A. F. M.Â López. 2005. Pérdidas de suelo y nitrógeno por escorrentía en un Ultisol degradado bajo diferentes condiciones de cobertura vegetal en Chaguaramas-Guárico. Agronomía Trop. 55(4): 475-496.

Urquiza, N., C. Alemán, L. Flores, M. Ricardo y Y. Aguilar. 2011. Manual de procedimientos para manejo sostenible de tierras. Cuba: Editorial CIGEA. 